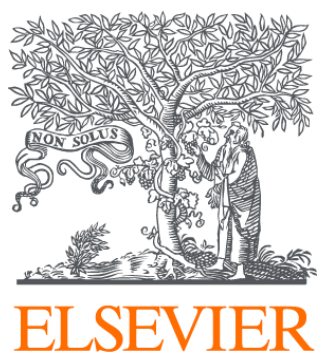

Since January 2020 Elsevier has created a COVID-19 resource centre with free information in English and Mandarin on the novel coronavirus COVID-

19. The COVID-19 resource centre is hosted on Elsevier Connect, the company's public news and information website.

Elsevier hereby grants permission to make all its COVID-19-related research that is available on the COVID-19 resource centre - including this research content - immediately available in PubMed Central and other publicly funded repositories, such as the WHO COVID database with rights for unrestricted research re-use and analyses in any form or by any means with acknowledgement of the original source. These permissions are granted for free by Elsevier for as long as the COVID-19 resource centre remains active. 


\section{Surrogate viruses for testing virucidal efficacy of chemical disinfectants}

\section{J. Steinmann*}

\section{Mikrolab GmbH, Norderoog 2, D-28259 Bremen, Germany}

\section{KEYWORDS \\ Surrogate viruses; Virucidal efficacy; HBV; HCV; Norovirus}

\section{Introduction}

The importance of viruses in causing nosocomial infections is well recognized, and the incidence of such infections continues to increase. The risk is particularly high in departments carrying out invasive procedures as well as in departments with young, elderly and immunosuppressed patients. There are many anecdotal reports on nosocomial infections, but no recent epidemiological studies.

Disinfection is one of the most effective measures for prevention of nosocomial virus

${ }^{*}$ Tel.: + 49-421-27819102; fax: +49-421-2760283.

E-mail address: mikrolab.gmbh@t-online.de infections. Therefore, there is an urgent need to assess the virucidal efficacy of hand-, surface- and instrument disinfectants in order to interrupt chains of infection in hospitals and other medical areas.

Since viruses are quite different from bacteria, inactivation results based upon bacteriological studies cannot be applied to viruses. Furthermore, the great heterogenicity of human pathogenic viruses makes it difficult to choose the most suitable viruses for assessing virucidal efficacy in vitro and in vivo.

In Europe, virucidal testing is performed in a stepwise procedure. As screening examinations of single compounds are not as relevant as in 
bacteriology, no phase 1 test (basic test) exists. Most of the experiments are performed with a quantitative suspension test (phase 2, step 1) allowing the demonstration of a virucidal efficacy with constant parameters such as temperature, volume ratios and a defined soil load. Phase 2 , step 2 methods describe procedures simulating practical conditions.

According to the German Guideline of the Federal Health Office (Bundesgesundheitsamt = BGA, now Robert Koch-Institute, Berlin, Germany) and of the German Association for the Control of Virus Diseases e.V. (DVV) a titre reduction of $10^{4}$ fold is necessary for demonstrating efficacy in suspension tests. ${ }^{1}$ The European draft of a guideline also requires the same reduction with identical volume ratios for confirming the virus-inactivating properties of a chemical disinfectant. ${ }^{2}$

Besides volume ratios and soil load, the choice of test viruses is one of the most important question in addressing inactivation experiments. In North America, each virus which can cause nosocomial infection is regarded as a test virus. In Europe, model viruses have been chosen that are representative of a wide range of virus families. In Germany, poliovirus type 1 (vaccine strain LSc 2ab, formerly strain Mahoney/Pette), adenovirus type 5 (formerly adenovirus type 2), papovavirus strain 777 and vaccinia virus strain Elstree are test viruses for hand-, surface- and instrument disinfectant. ${ }^{1}$ In Europe (prEN 14476), only the polio- and the adenoviruses are chosen. ${ }^{2}$ Additionally, bovine parvovirus is incorporated into the guideline for the evaluation of instrument disinfectant due to its heat stability. In Germany, the Robert KochInstitute and the DVV plan to divide the requirements of disinfection into high level (polio- and adenovirus inactivation necessary) and low level (only inactivation of bovine viral diarrhea virus and vaccinia virus necessary).

Besides the viruses mentioned in the guidelines, there are other important pathogens such as Hepatitis B virus (HBV), Hepatitis C virus (HCV) and norovirus which cause nosocomial infections but cannot be propagated sufficiently by cell culture techniques. Due to their importance, these agents would be part of the guidelines if culture were possible. Because they are not culturable, surrogate viruses have been introduced into virucidal testing.

$\mathrm{HBV}$ and HCV are the most prevalent bloodborne pathogens. Noroviruses, first detected in faecal specimens, are now responsible for many outbreaks of gastro-enteritis following the introduction of molecular techniques into virus detection.

A further use of surrogate viruses is when the virus needs a level of containment which is not readily available. For example, the recently detected virus causing severe acute respiratory syndrome (SARS), which belongs to the family Coronaviridae and requires a high level of laboratory safety. ${ }^{3}$ Both bovine coronavirus (BCV) and the avian infectious bronchitis virus (IBV) resemble this new virus and may serve as surrogates in the future. Table I lists the four important surrogate viruses. The importance of surrogates for virucidal testing of $\mathrm{HBV}, \mathrm{HCV}$ and norovirus will be discussed in detail.

\section{Duck hepatitis B virus (surrogate of HBV)}

Human HBV belongs to the family of Hepadnviridae and is a serious viral pathogen in man that is highly contagious and can spread through blood, saliva and semen. HBV is a small, enveloped DNA virus (40-48 $\mathrm{nm}$ in diameter) that replicates its partially double-stranded DNA genome through reverse transcription of an RNA intermediate. The total genome is $3020-3320$ nucleotides for the full, and 1700-2880 nucleotides for the short, length strand, respectively. Hepadnaviruses employ an episomal covalently closed circular DNA as a nuclear transcription template and establish a DNA pool to regulate gene expression by a copy number. They are noncytopathic viruses and often establish a long-term persistent infection. In the past, a variety of approaches to study inactvation of HBV were utilised due to the lack of sufficient cell culture replication (Table II).

The chimpanzee test system allows the use of human HBV itself in the test, but the small number of available animals limits its relevance for proper testing of chemical disinfectants. The so-called indirect tests like the morphologic alteration and disintegration test (MADT), DNA polymerase inactivation and the HBsAg test do not reflect our increased knowledge of HBV. Adaption experiments with a cell culture of the hepatoma cell line HepG2 showed only a small effect. ${ }^{4}$ A molecular approach based upon the destruction of sequential epitopes and the inability to amplify the target sequence

Table I Surrogate viruses used in virucidal testing of disinfectants

\begin{tabular}{ll}
\hline Test virus & Surrogate virus \\
\hline Hepatitis B virus & Duck hepatitis B virus (DHBV) \\
Hepatitis C virus & Bovine viral diarrhea virus (BVDV) \\
Norovirus & Feline calicivirus (FCV) \\
SARS virus & Bovine coronavirus (BCV) or avian \\
& infectious bronchitis virus (IBV) \\
\hline
\end{tabular}


Table II Different approaches to inactivation studies with HBV

Intravenous inoculation of chimpanzees

Primary human hepatocyte culture

Surrogate markers

Other hepadnaviruses

HBV DNA

Human hepatoma cell line (HepG2)

with a polymerase chain reaction (PCR) needs further investigations. ${ }^{5}$ Recently, the Asian tree shrew, Tupaia belangeri, was introduced as a novel animal model. ${ }^{6}$ The primary tupaia hepatocytes are susceptible to infection with HBV and woolly monkey hepatitis B virus (WMHBV). Inactivation assays with HBV and these hepatocytes may allow disinfection experiments in the future.

In addition to HBV, Hepadnaviruses include a growing number of viruses that infect selected hosts in the wild (Table III). The ground squirrel, the woodchuck hepatitis virus and the duck hepatitis $B$ virus (DHBV) are best studied. Non-human hepadnaviruses are useful not only for studying antiviral drug development and evaluation of antiviral compounds mainly in the blood product industry but also for inactivation experiments with disinfectants. DHBV (genus avihepadnavirus) shares many physical properties with the closely related $\mathrm{HBV}$ and the mechanism for initiating and inducing a long-term infection is similar. However, DHBV lacks the open reading frame for a multifunctional protein termed $\mathrm{HBx}$. Furthermore, its genome and the single-stranded gap of the partially doublestranded DNA is slightly smaller.

However, DHBV has often been used as an in-vivo model for the preclinical evaluation of nucleoside analogs and in blood product industry and therefore this virus was also introduced into inactivation studies by Murray and co-workers. ${ }^{7}$ Two methods of

Table III The members of the Hepadnaviridae

\begin{tabular}{ll}
\hline $\begin{array}{l}\text { Genus orthohepadnavirus } \\
\text { Primates }\end{array}$ & Hepatitis B virus \\
& Orangutan hepadnavirus \\
& Woolly monkey hepatitis B virus \\
Rodentia & Artic squirrel hepatitis B virus \\
& Ground squirrel hepatitis B virus \\
& Woodchuck hepatitis B virus
\end{tabular}

Genus Avihepadnavirus

Pekin duck hepatitis $B$ virus Grey heron hepatitis B virus Crane hepatitis $B$ virus Snow goose hepatitis $B$ virus Ross goose hepatitis $B$ virus White stork hepatitis $B$ virus laboratory testing based on the susceptibility of hepatocytes of the Pekin duck exist. First, titration can be performed in day-old ducklings followed by bleeding nine weeks after infection and detection of DHBV DNA by Southern blotting or by PCR. However, as a large number of animals and special housing are required and the time for results is considerable, in vitro systems have been developed. Thus, hepatocytes can be prepared from embryonated eggs (day 17-21) and after infection the virus can be detected by immunofluorescence or quantitative PCR.

The susceptibility of DHBV to sodium hypochlorite and sodium dichloroisocyanate was compared with the susceptibility of HBV to these substances. ${ }^{8}$ The results demonstrate a good correlation between inactivation of infectivity in vivo and the total inhibition of the in vitro hepadnavirus DNA polymerase activity. With the DHBV model it has been possible to study the capability of a hydrogen peroxide gas plasma sterilizer. ${ }^{9}$ By assessing the efficacy of two quaternary ammonium chloride disinfectants with a PCR for DNA detection, concentrations of 1200 and 1800 ppm were found to be effective against DHBV. ${ }^{10}$ Later on, a quantitative PCR was developed based on $\mathrm{SyBr}$ green dye. ${ }^{11}$ The DHBV model clearly demonstrated the importance of cleaning angioscopes before disinfection and sterilisation. ${ }^{12}$

Further experiments will be needed to study the HBV inactivating properties of many disinfectants which have not been evaluated by the chimpanzee model in the past.

\section{Bovine viral diarrhea virus (surrogate of HCV)}

$\mathrm{HCV}$ is a member of the family Flaviviridae containing three genera. ${ }^{13}$ The genus Hepacivirus contains exclusively HCV. Flavivirus as another genus contains among others the yellow fever virus group, the dengue group and the tick-born encephalitis virus group. The border disease virus, the hog cholera virus and the bovine viral diarrhea virus (BVDV) belong to the third genus Pestivirus. The characteristics of the family Flaviviridae are shown in Table IV.

There are no in-vitro tests with HCV. Recently, the ability of a Vero cell clone to bind HCV to cell surface receptors was introduced in disinfectant testing. ${ }^{14}$ Phenolics and a chlorine-based compound were active, indicating that this enveloped virus is not unduly resistant. ${ }^{15}$ Additionally, a RT-PCR was described for testing antiseptic/disinfectant 


\begin{tabular}{ll} 
Table IV & Characteristics of flaviviridae \\
\hline Host & $\begin{array}{l}\text { Arthropods and vertebrates } \\
\text { Lenomear, single-stranded positive sense RNA } \\
9500-12500 \text { nucleotides long }\end{array}$ \\
Morphology & $\begin{array}{l}\text { Spherical to pleomorphic, } 40-60 \mathrm{~nm} \text { in } \\
\text { diameter isometric nucleocapsid virions are } \\
\text { enveloped and composed of } 15-20 \% \text { lipids } \\
\text { by weight } \\
\text { Lipid solvent, urea and betapropiolactone } \\
\text { inactivate flavivirus }\end{array}$ \\
\hline
\end{tabular}

activity. ${ }^{16}$ In these experiments, the importance of adding detergent to a sodium hypochlorite solution was demonstrated. Despite these efforts, the narrow host range and the lack of suitable cell culture systems for HCV have encouraged the use of surrogate viruses. The most promising way for inactivation experiments was the introduction of the BVDV.

In contrast to HBV, there is no closely-related animal virus for HCV. BVDV, like HCV, is a small, enveloped, positive-stranded RNA virus. The BVDV genome is approximately $12.3 \mathrm{~kb}$ in length with a $5^{\prime}$ nontranslated region (NTR), a single large open reading frame (ORF), and a $3^{\prime}$-NTR lacking a poly(A)tail. The ORF is translated into a single polyprotein that is co- and post-translationally cleaved into 11 or 12 mature proteins by a combination of viral and host proteases.

The BVDV was chosen as a surrogate because there are similarities in terms of genome structure and mode of replication. Data with BVDV inactivation in a quantitative suspension test by chemical germicides are not available, since the great susceptibility of the virus to these substances has not initiated such studies in the past.

\section{Feline calicivirus (surrogate of norovirus)}

Norovirus (formerly Norwalk-like viruses, Norwalk viruses or small round structured viruses) is a genus within the family Caliciviridae and causes acute gastro-enteritis in humans. ${ }^{17}$ Norovirus infections are typically mild and self-limited. The disease is characterized by an abrupt onset, a short duration and a high proportion of those infected having diarrhoea, abdominal cramps and vomiting. People become infected by faecal-oral transmission via contaminated water and food, by hand-to-mouth transfer from contaminated surfaces, by ingestion of aerosolised vomit and by secondary person-toperson transmission. Outbreaks have been reported in many places e.g. in hospitals, residential homes, recreational camps, schools and hotels, and on cruise ships. These outbreaks often seem to be the result of more than one mode of transmission.

Criteria for suspected outbreaks are vomiting in $>50 \%$ of cases, short duration of illness, an incubation period of 15-48 h and involvement of staff and patients. Control measurements consist of cohorting of staff and individuals, wearing gloves, hand disinfection and washing, excluding affected staff, cleaning and disinfecting vomit and faecal spillages promptly. ${ }^{18}$

In contrast to both hepatitis viruses, noroviruses are non-enveloped. The viruses contain one molecule of linear positive-sense RNA. The virion is $27-40 \mathrm{~nm}$ in diameter. The genome encodes the non-structural proteins at the $5^{\prime}$ end and a single major capsid protein towards the $3^{\prime}$ end. The family Caliciviridae contains four genera: norovirus, sapovirus, lagovirus and vesivirus.

The public health impact of norovirus infections is increasingly recognised. Furthermore, the contamination of the environment and the importance of human hands as vehicles for virus transmission have focussed the interest on adequate virus inactivation by hand- and surface disinfectants.

Like HBV and HCV, there is no suitable cell culture system to support the replication of noroviruses. The use of feline calicivirus (FCV) which shares many similarities with noroviruses ${ }^{19}$ was introduced as a surrogate by Slomka and Appleton. ${ }^{20}$ Recently, a plaque assay with Crandell Rees feline kidney cells was established. ${ }^{21}$ This method will provide an alternative to end-point titration assays for quantitative experiments with FCV in inactivation studies.

There are few published inactivation experiments with FCV. Scott and co-workers studied 35 products mainly used in veterinary medicine; 11 were virucidal for FCV after an exposure time of 10 min. ${ }^{22}$ Alcohols such as 50\% propan-2-ol, 50\% ethanol and 35\% methyl alcohol were not effective, whereas phenolics, clorox, aldehydes and creolin inactivated the test virus. In another study, $0.5 \%$ glutaraldehyde and $1000 \mathrm{ppm}$ hypochlorite were effective within one minute, whereas $1: 10$ quaternary ammonium, $75 \%$ ethanol and $1 \%$ anionic detergents failed to demonstrate virucidal efficacy within this exposure time. ${ }^{23}$

Our own experiments with various $70 \%$ alcoholic solutions (ethanol, propan-1-ol, propan-2-ol) on artifically contaminated fingerpads according to E 1838-02 of American Society for Testing and Material (ASTM) ${ }^{24}$ showed that ethanol with $30 \mathrm{~s}$ exposure time was superior to the other types of alcohol. Among different soil loads 5\% foetal calf serum had no inhibitory effect on the inactivation process, whereas a tripartite soil load according to 
7.2.4. of $E 1838-02$ and a $5 \%$ faecal suspension reduced the FCV inactivating properties of ethanol and propan-1-ol on contaminated fingerpads.

\section{Conclusions}

The introduction of surrogate viruses has provided important information on the behaviour of certain important human pathogenic viruses in the past. Although they are not incorporated into official guidelines by standard-setting organisations, the US Environmental Protection Agency (EPA) has allowed label claims for human HBV after testing with DHBV since August 2000 (virucides DIS/TSS-7/1981). Even the labeling disclaimer to indicate that the disinfectant has been tested against DHBV is unnecessary. This shows the important role of animal virus testing and the use of appropiate surrogates in disinfection experiments.

The World Health Organisation has recently declared that there are no new infections with the virus of severe acute respiratory syndrome (SARS), but the possibility of its remergence still exists. Epidemiological data seem to suggest that the virus is spread by droplets or by direct and indirect contact, although airborne spread cannot be excluded. If transmission by indirect contact plays an important role, disinfection with products of proven efficacy is critical. Due to the high risk of working in the laboratory with this new coronavirus, surrogates such as bovine coronavirus or avian infectious bronchitis virus could provide acceptable replacements for the SARS virus in chemical disinfectant testing.

At present, our inactivation data with DHBV, BVDV and FCV are limited, but established cell culture systems with these viruses will allow more information on the behaviour and inactivation of important viruses causing nosocomial infections. The introduction of DHBV by the EPA shows that these surrogate viruses can be incorporated into official guidelines.

\section{References}

1. Guidelines of Bundesgesundheitsamt (BGA; German Federal Health Office) and Deutsche Vereinigung zur Bekämpfung der Viruskrankheiten e.V. (DVV; German Society for the Control of Virus Diseases) for testing the effectiveness of chemical disinfectants against viruses. Zbl Hyg 1990;189:554-562.

2. prEN 14476. Chemical disinfectants and antiseptics-virucidal quantitative suspension test for chemical disinfectants and antiseptics used in human medicine-Test method and requirements (phase 2 , step 1); 2002.

3. Drosten C, Gunther S, Preiser W, et al. Identification of a novel coronavirus in patients with severe acute respiratory syndrome. N Engl J Med 2003;348:1967-1976.

4. Payan C, Cottin J, Lemarie C, Ramont C. Inactivation of hepatitis $\mathrm{B}$ virus in plasma by hospital in-use chemical disinfectant assessed by a modified HepG2 cell culture. $J$ Hosp Infect 2001;47:282-287.

5. Jursch CA, Gerlich WH, Glebe D, Schaefer OM, Thraenhart O. Molecular approaches to validate disinfectants against human hepatitis B virus. Med Microbiol Immunol 2002;190: 189-197.

6. Kock J, Nassal M, MacNelly S, Baumert TF, Blum HE, von Weizsacker F. Efficient infection of primary tupaia hepatocytes with purified human and woolly monkey hepatitis B virus. J Virol 2001;75:5084-5089.

7. Murray SM, Freiman JS, Vickery K, Lim D, Cossart YE, Whiteley RK. Duck hepatitis B virus: a model to assess efficacy of disinfectants against hepadnavirus infectivity. Epidemiol Infect 1991;106:435-443.

8. Tsiquaye KN, Barnard J. Chemical disinfection of duck hepatitis B virus: a model for inactivation of hepatitis B virus. J Antimicrob Chemother 1993;32:313-323.

9. Vickery K, Deva AK, Zou J, Kumaradeva P, Bissett L, Cossart YE. Inactivation of duck hepatitis $B$ virus by a hydrogen peroxide gas plasma sterilization system: laboratory and 'in use' testing. J Hosp Infect 1999;41:317-322.

10. Wang C-YJ, Giambrone JJ, Smith BF. Development of viral disinfectant assays for duck hepatitis B virus using cell culture/PCR. J Virol Methods 2002;106:39-50.

11. Wang C-YJ, Giambrone JJ, Smith BF. Comparison of cell culture systems for duck hepatitis $B$ virus using $\mathrm{SyBr}$ green quantitative PCR. J Virol Methods 2002;106:175-184.

12. Chaufour X, Deav AK, Vickery $\mathrm{K}$, et al. Evaluation of disinfection and sterilization of reusable angioscopes with the duck hepatitis B model. J Vasc Surg 1999;30: 277-282.

13. Ohba K, Mizokami M, Lau JY, Orito E, Ikeo K, Gojobori T. Evolutionary relationship of hepatitis $C$, pest- flavi-, plant viruses and newly discovered GB hepatitis agents. FEBS Lett 1996;378:232-234.

14. Valli MB, Carloni G, Manzin A, Nasorri F, Ponzetto A, Clementi M. Hepatitis $C$ virus infection of a Vero cell clone displaying efficient virus-cell binding. Res Virol 1997;148: 181-186.

15. Agoloni G, Russo A, Clementi M. Effect of phenolic and chlorine disinfectants on hepatitis $\mathrm{C}$ binding and infectivity. Am J Infect Control 1999;27:236-239.

16. Charrel RN, de Chesse R, Decaudin A, De Micco P, de Lamballerie $X$. Evaluation of disinfectant efficacy against hepatitis $C$ virus using a RT-PCR-based method. $J$ Hosp Infect 2001;49:129-134.

17. Lopman BA, Brown DW, Koopmans M. Human calicivirus in Europe. J Clin Virol 2002;24:137-160.

18. Chadwick PRG, Beards D, Brown EO, et al. Management of hospital outbreaks of gastro-enteritis due to small roundstructured viruses. J Hosp Infect 2000;46:1-10.

19. Jiang $X$, Wang $M$, Wang K, Estes MK. Sequence and genomic organization of Norwalk virus. Virology 1993;195:51-61.

20. Slomka MJ, Appleton H. Feline calicivirus as a model system for heat inactivation studies of small round structured viruses in shellfish. Epidemiol Infect 1998;121:401-407.

21. Bidawed S, Malik N, Adegunrin O, Sattar SS, Farber JM. A feline kidney cell line-based plaque assay for feline calicivirus, a surrogate for Norwalk virus. J Virol Methods 2003;107:163-167.

22. Scott FW. Virucidal disinfectants and feline viruses. Am J Vet Res 1980;41:410-414. 
23. Doultree JC, Druce JD, Birch CJ, Bowden DS, Marshall JA. Inactivation of feline calicivirus, a Norwalk virus surrogate. $J$ Hosp Infect 1999;41:51-57.

24. ASTM International, 2002, Standard test method for deter- minating the virus-eliminating effectiveness of liquid hygienic handwash and handrub agents using the fingerpads of adult volunteers. Designation: E-1838-02. West Conshohocken, PA: ASTM; 2002. 